\title{
PEMETAAN TABEL RELATIONSHIP DALAM VISUALISASI DIAGRAM RELASI UNTUK EKSPLORASI DATA PADA DATABASE
}

\author{
Siti Julaeha ${ }^{1}$, Nunu Kustian ${ }^{2}$, Dudi Parulian ${ }^{3}$ \\ Program Studi Teknik Informatika, Universitas Indraprasta PGRI \\ nyooi.sholeha@gmail.com
}

Submitted July 14, 2020; Revised November 16, 2020; Accepted November 20, 2020

\begin{abstract}
Abstrak
Visualisasi sebagai alat memudahkan untuk memahami informasi dengan cepat yang disajikan dalam bagan maupun grafik. Tujuan visualisasi adalah agar dapat memudahkan ekplorasi data. Oleh karena itu, penulis menggunakan Diagram Relasi sebagai Pemodelan Matematika untuk mengeksplorasi data yang mempunyai hubungan relasi antar tabel atau tabel relationship. Tujuan penelitian ini untuk memetakan dataset didalam database, jika ada kemungkinan beberapa data dalam atribut terjadi kesalahan penginputan. Pada proses pemetaan, penulis menggunakan komposisi relasi, sehingga membuat banyaknya kemungkinan terjadinya relasi pada pemetaan. Karena terjadi masalah pada komposisi tabel, pemetaan tabel relationship dilakukan ke dalam relasi secara biner berdasarkan jumlah atribut didalam suatu tabel. Kesimpulan didapatkan pada saat menggunakan Diagram Relasi secara biner adalah semakin banyak atribut pada tabel, maka semakin banyak pemetaan diagram relasi yang harus digambarkan. Walaupun diagram relasi menjadi sangat kompleks, hal ini dapat ditangani jika tabel-tabel tersebut dinormalisasikan dengan baik.
\end{abstract}

Kata Kunci : Visualisasi, Eksplorasi Data, Diagram Relasi, Tabel Relationship, Database

\begin{abstract}
Visualization is a tool that makes it easy to understand the information presented in charts and graphs. The purpose is to facilitate data exploration. Therefore, the authors use relationship diagrams as Mathematical Modeling to explore data that has a relationship between tables. The purpose of the study is to map the dataset, which found out a possibility that some errors when entering data. In the mapping process, we use the composition of relations, thus making the number of possible relationships in the mapping. Because of the problem, the table mapping use into a binary relationship diagram based on the number of attributes in a table. The conclusion obtained when using a binary relation diagram is that the more column in a table, the more mapping relationship diagrams must be drawn. Although the relationship diagram becomes very complex, it handled if the tables are correctly normalized.
\end{abstract}

Key Words : Visualization, Data Exploration, Relationship Diagram, Relationship Table, Database

\section{PENDAHULUAN}

Visualisasi data sering digunakan untuk interpretasi data dalam bentuk grafik ataupun bagan. Tujuan visualisasi tersebut sebagai alat memudahkan untuk memahami informasi dengan cepat. Sebagian besar visualisasi data untuk mempresentasikan statistik berdasarkan categorical dan numerical. Penelitian yang disajikan oleh [1], memperlihatkan beberapa grafik seperti histogram dan scatter plot agar dapat dilakukan eksplorasi data berdasarkan relasi antar atribut.

Visualisasi data dapat pula berdasarkan pemodelan matematika dengan menggunakan teorema Pythagoras untuk mengeksplorasi dataset ke dalam Pohon Pythagoras [2] dengan mempresentasikan asosiasi atau hubungan IF-THEN dalam dataset. 
Jika membahas mengenai dataset, tidak lepas hubungannya dengan sebuah database. Rancangan yang sering disajikan dalam database pada beberapa penelitian seperti [3]-[6], sebagian besar menggunakan Entity Relatioship Diagram (ERD). Penelitian dari [7] menggunakan alternatif lain berdasarkan pemodelan matematika, dimana perancangan dapat dilakukan dengan menggunakan Diagram Venn sebagai visualisasi hubungan antar atribut. Diagram Venn lebih mudah dipahami bagaimana hubungan relasi secara kompleks berdasarkan operasi himpunan Irisan dan Gabungan, jika dibandingkan menggunakan ERD.

Kemudian, jika dilakukan observasi lebih mendalam. Hubungan relasi tersebut tidak lepas dari adanya pengaruh dari sebuah atribut kunci yang terdiri dari Primary Key (PK) dan Foreign Key (FK) untuk menghubungkan antara dua tabel.

Berdasarkan visualisasi data yang dibahas sebelumnya, bahwa konsep dari visualisasi adalah mengekplorasi data. Oleh karena itu, Diagram Venn tidak dapat dilakukan.

Penulis menggunakan Diagram Relasi sebagai Pemodelan Matematika untuk mengeksplorasi data yang mempunyai hubungan relasi antar tabel atau tabel relationship berdasarkan atribut kunci. Hal ini Foreign Key berperan penting sebagai penghubung Primary Key. Tujuan penelitian ini untuk memetakan dataset didalam database, jika ada kemungkinan beberapa data dalam atribut terjadi kesalahan penginputan. Konsep ini hampir sama dengan penelitian [8], sehingga data dapat diselusuri dengan baik. Hasil penelitian ini memudahkan eksplorasi data yang telah diinput dengan disajikan dalam visualisasi Diagram Relasi.

\section{METODE PENELITIAN}

Tahap-tahap yang dapat dilakukan untuk pemetaan tabel relationship antara lain: a) Normalisasi

Pemetaan tabel relationship tidak dapat dilakukan jika tabel pada database tidak normalisasi. Tujuan normalisasi adalah menghindari adanya redudansi data dengan mengelompokkan dataset yang mempunyai ketergantungan pada atribut ke dalam tabel. Beberapa tahap yang dilakukan untuk menormalisasi antara lain [9]:

1) $1 \mathrm{NF}$

Setiap dataset pada tiap-tiap atribut sudah mempunyai satu nilai data.

2) $2 \mathrm{NF}$

Memisahkan atribut-atribut yang mempunyai ketergantungan terhadap atribut Primary Key dan membentuk tabel relationship. Pada tahap ini relasi terjadi dikarenakan adanya Foreign Key didalam tabel relationship.

3) $3 \mathrm{NF}$

Relasi terjadi jika pada tabel relationship terdapat atribut yang menjadi calon key berdasarkan nilai value data (dapat diuji dengan asosiasi IF-THEN).

b) Diagram Relasi

Relasi pada umumnya merupakan hubungan antara dua himpunan A, B berdasarkan aturan tertentu. Aturan tersebut dinamakan relasi biner.

Relasi biner dinyatakan sebuah notasi $(\mathrm{A}, \mathrm{B}) \in \mathrm{R}$ yang berarti himpunan $\mathrm{A}$ dihubungkan ke himpunan $\mathrm{B}$ oleh $\mathrm{R}$. Himpunan A dapat disebut sebagai domain dari $\mathrm{R}$ dan himpunan A sebagai range dari $\mathrm{R}[10]$. Pemetaan Relasi yang penulis lakukan menggunakan dua metode yaitu diagram panah dan himpunan pasangan berurutan.

1) Diagram Panah

Diagram panah termasuk komponen diagram relasi, dimana membentuk pola dalam gambar panah yang menghubungkan 
himpunan anggota A dan B. Contoh Diagram Panah himpunan A dan B [11] dapat dilihat pada gambar dibawah ini:

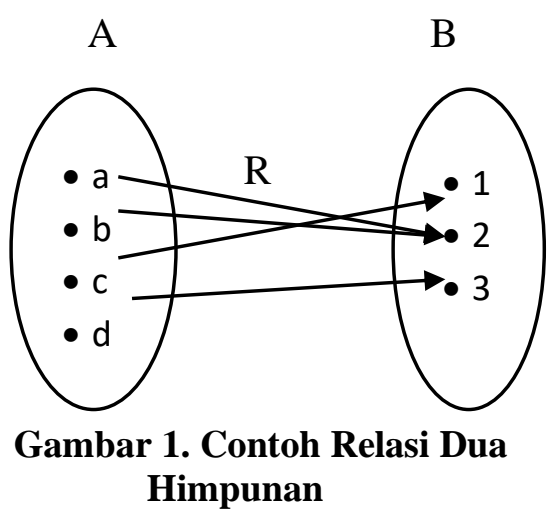

2) Himpunan Pasangan Berurutan

Himpunan pasangan berurutan menghubungkan suatu himpunan yang satu dengan yang lain. Sistematika penulisannya antara lain anggota himpunan A ditulis pertama (Domain), sedangkan anggota himpunan B yang menjadi pasangannya ditulis ke dua (Range). Contoh himpunan berpasangan berurutan pada Gambar 1, domain = $\{\mathrm{a}, \mathrm{b}, \mathrm{c}, \mathrm{d}\}$, range $=\{1,2,3\}$, maka himpunan pasangan berurutan yaitu: $\{(\mathrm{a}, 2),(\mathrm{b}, 2),(\mathrm{c}, 1),(\mathrm{d}, 3)\}$.

Pemodelan relasi yang lebih dari dua himpunan, dapat dibuat berdasarkan tabel di bawah ini:

Tabel 1. Jumlah Relasi Berdasarkan n Himpunan

\begin{tabular}{ccccccc}
\hline Himpunan & $\mathbf{2}$ & $\mathbf{3}$ & $\mathbf{4}$ & $\mathbf{5}$ & $\mathbf{6}$ & $\mathbf{7}$ \\
\hline Deretan Ke- & & & & & & \\
$(\mathrm{n}-1)$ & 1 & 2 & 3 & 4 & 5 & 6 \\
Relasi & 1 & 3 & 6 & 10 & 15 & 21 \\
\hline
\end{tabular}

Diagram relasi yang dapat dibuat pada $n$ himpunan berdasarkan persamaan sebagai berikut:

$$
U_{n}=\frac{1}{2}(n(n+1))
$$

Selain itu, alternatif lain pada himpunan yang lebih dari dua dapat menggunakan komposisi relasi untuk eksplorasi data secara keseluruhan, antara lain sebagai berikut [10]:

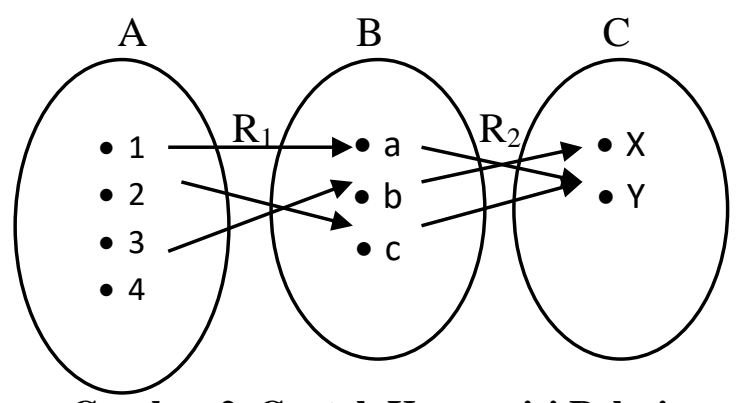

Gambar 2. Contoh Komposisi Relasi

Berdasarkan pada Gambar 2, $\mathrm{R}_{1}=\{(1, \mathrm{a})$, $(2, c),(4, b)\}, R_{2}=\{(a, Y),(c, Y),(b, X)\}$. Berarti komposisi relasi $\mathrm{R}_{1}$ dan $\mathrm{R}_{2}$ atau $\left(\mathrm{R}_{1}\right.$ o $\left.\mathrm{R}_{2}\right)$ adalah $\{(1, \mathrm{Y}),(2, \mathrm{Y}),(4, \mathrm{X})\}$.

Penulis melakukan eksplorasi data dalam tabel relationship yang diambil dari dasar pemikiran pada penelitian [9] sebagai sampel. Berdasarkan pengamatan yang telah dilakukan, ditemukan beberapa kesalahan normalisasi sehingga relasi pada tabel tidak sempurna, seperti terdapat atribut Primary Key yang belum dipisahkan. Sehingga Penulis perlu menyempurnakan normalisasi agar tabel relationship dapat dibuat berdasarkan Primary Key dan Foreign Key, dengan menggunakan dataset dan atribut berbeda namun tidak merubah pola tabel pada penelitian yang dilakukan oleh [9].

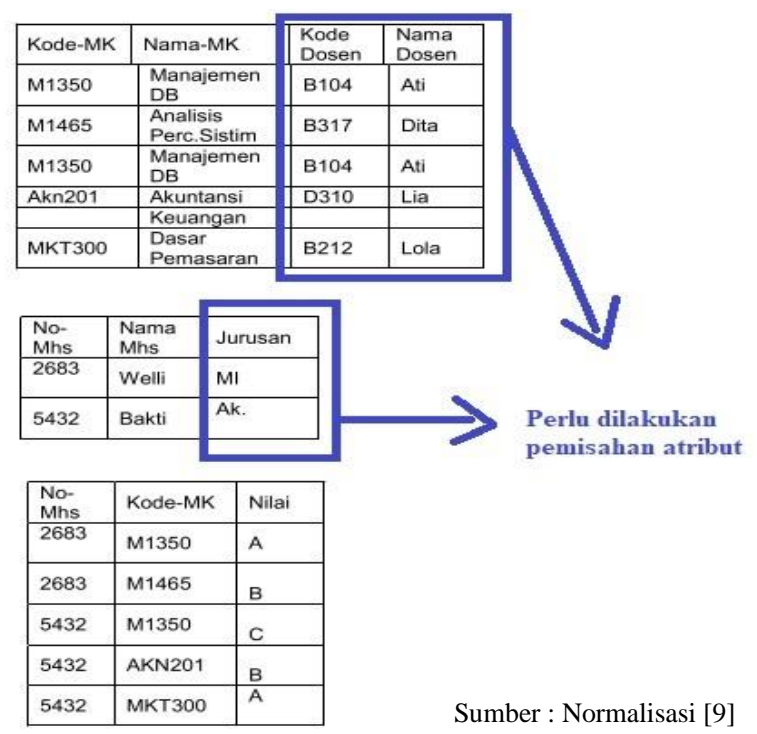

Gambar 3. Normalisasi Belum Sempurna 


\section{HASIL DAN PEMBAHASAN}

Berikut adalah normalisasi dengan 2NF:

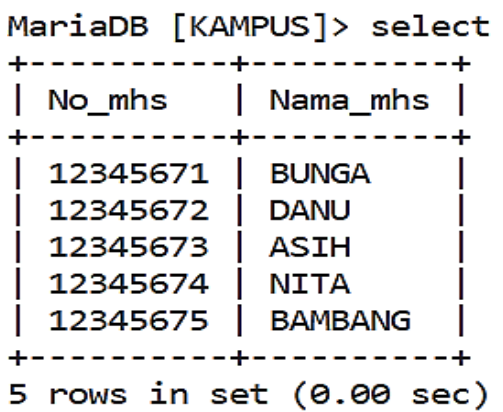

Gambar 4. Tabel MHS

MariaDB [KAMPUS]> select * from JURUSAN;

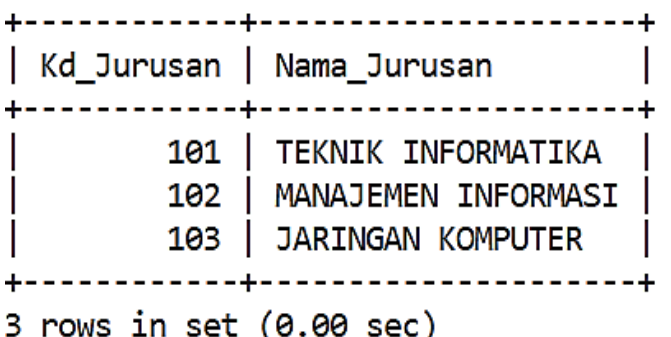

Gambar 5. Tabel JURUSAN

MariaDB [KAMPUS]> select * from MATAKULIAH;

\begin{tabular}{|r|r|}
201 & $\mid$ SISTEM BASIS DATA | \\
202 & PEMROGRAMAN DASAR | \\
203 & SISTEM OPERASI
\end{tabular}

3 rows in set $(\theta . \theta 0 \mathrm{sec})$

Gambar 6. Tabel MATAKULIAH

MariaDB [KAMPUS] s select * from DOSEN;

\begin{tabular}{|l|l|}
301 & KANTAPRAWIRA \\
302 & NUNU KUSTIAN \\
303 & DUDI PARULIAN \\
304 & SITI JULAEHA \\
4 rows in set $(\theta .00 \mathrm{sec})$
\end{tabular}

\section{Gambar 7. Tabel DOSEN}

Berdasarkan gambar diatas, terdapat tabeltabel yang sudah dipisahkan dengan atribut sebagai berikut:
$\mathrm{MHS}=\{\underline{\text { No_mhs }}$, Nama_mhs $\}$

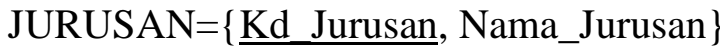

MATAKULIAH $=\{\underline{\text { Kd_MK}}$, Nama_MK $\}$

DOSEN $=\{\underline{\text { NIDN }}$, Nama_Dosen $\}$

Tabel yang dipisahkan yaitu MHS, JURUSAN, MATAKULIAH, dan DOSEN yang dimana Primary Key pada tabel merupakan atribut relasi (No_mhs, Kd_Jurusan, Kd_MK, dan NIDN) yang dihubungkan kedalam tabel relationship sebagai berikut:

MariaDB [KAMPUS]> select * from NILAI;

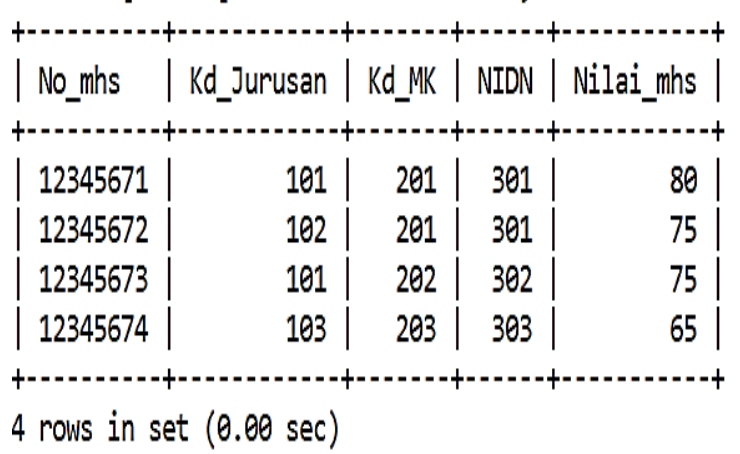

\section{Gambar 8. Tabel Relationship NILAI}

Pada Gambar 8, beberapa atribut mempunyai nama yang sama dengan Gambar 4 s/d 7. Berarti atribut ini merupakan Foreign Key dimana dataset di dalamnya bukan nilai yang unik (terdapat nilai data yang sama), tidak seperti pada Primary Key.

Dikarenakan atribut Foreign Key mempunyai nama yang sama dengan Primary Key. Maka, pemetaan untuk kedua atribut key tersebut dapat dihubungkan seperti berikut:

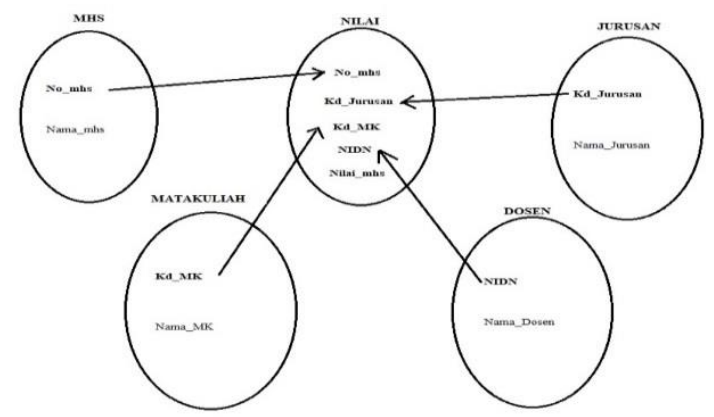

Gambar 9. Diagram Relasi Antar Key 
Penelusuran dataset dapat dilakukan dengan pemetaan dalam diagram relasi. Sebagai contoh tabel query pada gambar 10 dibawah ini:

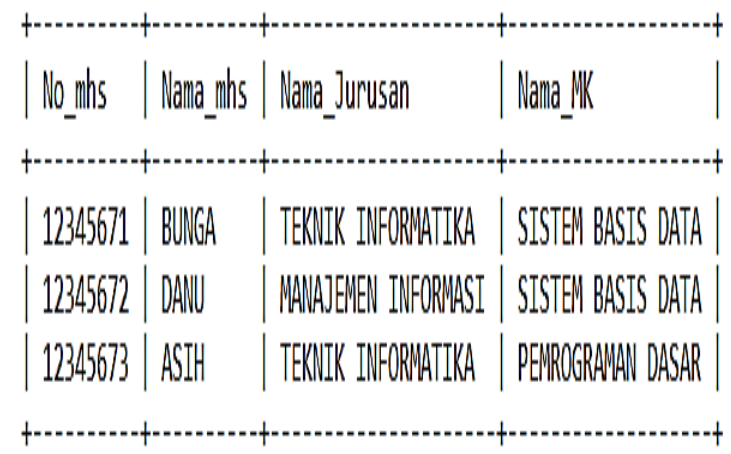

3 rows in set (0.08 sec)

\section{Gambar 10. Tabel Query}

Pada tabel diatas, berdasarkan perintah $S Q L$ :

Select MHS.No_mhs, MHS.Nama_mhs, JURUSAN. Nama_Jurusan, MATAKULIAH.Nama_MK from MHS, JURUSAN, MATAKULIAH, NILAI where MHS.No_mhs = Nilai.No_mhs and Jurusan.Kd_Jurusan $=$ NILAI.Kd_Jurusan and MATAKULIAH.Kd_MK = NILAI.Kd_MK and NILAI. Nilai_mhs $>=75$

Berarti tabel Query akan menampilkan No_mhs, Nama_mhs, Nama_Jurusan dan Nama_MK yang mempunyai Nilai $>=75$.

Eksplorasi data dapat dilakukan dengan membuat pemetaan tabel relationship Nilai. Pemetaan tersebut dengan membuat komposisi relasi sebagai berikut:

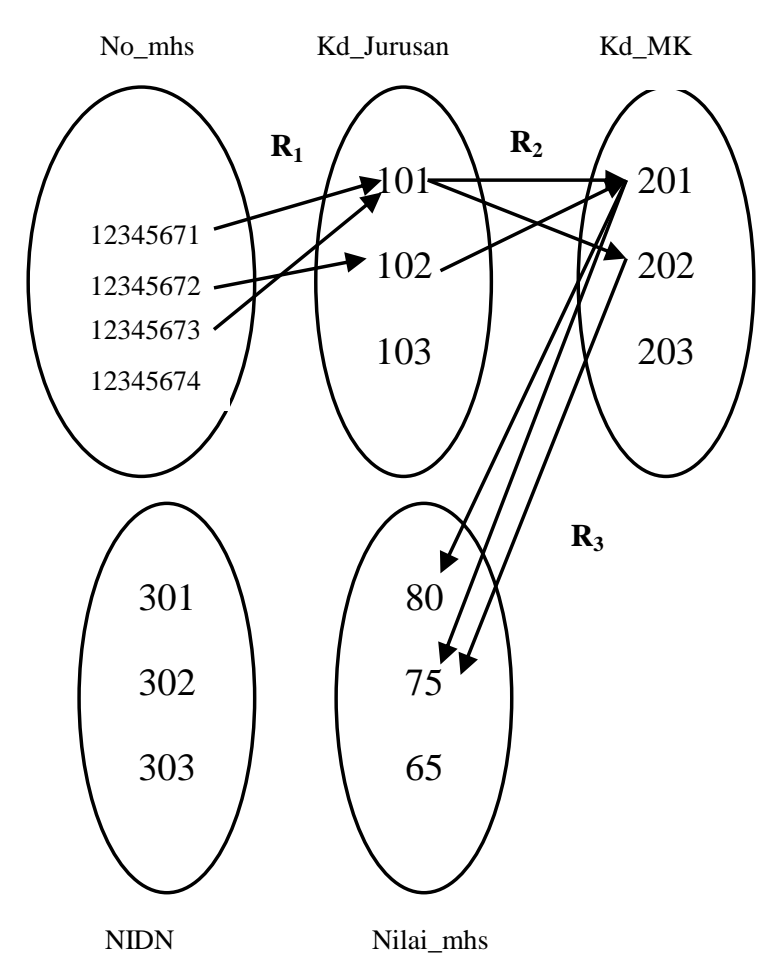

Gambar 11. Pemetaan Tabel Relationship

Relasi untuk $\mathrm{R}_{1}=\{(12345671,101)$, $(12345672,102),(12345673,101)\}, \mathrm{R}_{2}=$ $\{(101,201),(101,202),(102,201)\}, R_{3}=$ $\{(201,80),(201,75),(202,75)\}$

Berarti komposisi relasi dari $\mathrm{R}_{1}$ o $\mathrm{R}_{2}=$ \{(12345671,201), $\quad(12345671,202)$, (12345672,201)\}, $\quad(12345673,201)$, $(12345673,202)\}, R_{2}$ o $R_{3}=\{(101,80)$, $(101,75)\},(102,80),(102,75)\}, \mathrm{R}_{1}$ o $\mathrm{R}_{3}=$ $\{(12345671,80)$, $(12345672,80)$, $(12345671,75)$, $(12345672,75)$, $(12345673,80),(12345673,75\}$

Berdasarkan komposisi relasi, banyak kemungkinan yang dapat direlasikan sehingga dataset yang didapatkan akan menjadi tidak jelas, sehingga perlu dilakukan pemetaan relasi secara biner.

Oleh karena itu, pemetaan relasi dilakukan berdasarkan jumlah himpunan pada tabel relationship Nilai yang dimana mempunyai 4 atribut yaitu No_mhs, Kd_Jurusan, Kd_MK, Nilai_mhs (NIDN diabaikan karena tidak dibuat relasi pada 
tabel query). Atribut inilah yang dijadikan himpunan.

Deretan $=\mathrm{n}-1=4-1=3$

$\mathrm{U}_{3}=(3(3+1)) / 2=6$, sehingga pemetaan ada 6 diagram relasi dapat dibuat.
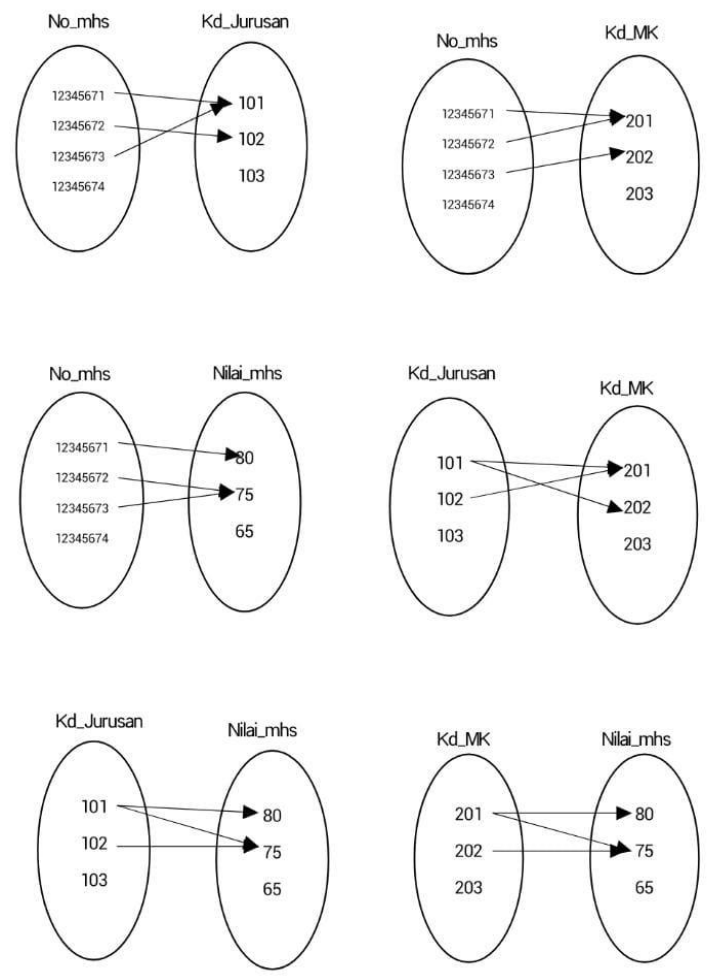

Gambar 12. Pemetaan Relasi Tabel Relationship Nilai

Berdasarkan Gambar 12, dapat simpulkan bahwa:

a) No_mhs $><$ Kd_Jurusan $=$

$\{(12345671,101),(12345672,102)$,

$(12345673,101)\}$

b) No_mhs $><$ Kd_MK = $\{(12345671,201),(12345672,201)$, $(12345673,202)\}$

c) No_mhs $><$ Nilai_mhs = $\{(12345671,80),(12345672,75)$, $(12345673,75)\}$

d) Kd_Jurusan $>\left\langle\mathrm{Kd} \_\mathrm{MK}=\{(101,201)\right.$, $(101,202),(102,201)\}$

e) Kd_Jurusan $><$ Nilai_mhs $=\{(101,80)$, $(101,75),(102,75)\}$ f) Kd_MK $><$ Nilai_mhs $=\{(201,80)$, $(201,75),(202,75)\}$

Jika berdasarkan tabel query pada Gambar 10, maka tabel-tabel seperti MHS, JURUSAN, dan MATAKULIAH dilakukan pemetaan seperti pada Gambar 12, data yang diambil adalah data yang sering muncul pada pemetaan Gambar 12 . Sehingga, hasil relasi yang didapatkan adalah:

a) $\mathrm{MHS}=\{(12345671, \mathrm{BUNGA})$, (12345672,DANU), (12345673,ASIH) $\}$

b) JURUSAN $=\{(101$, TEKNIK INFORMATIKA), (102,MANAJEMEN INFORMASI) \}

c) MATAKULIAH $=\{(201$, SISTEM BASIS DATA), (202,PEMROGRAMAN DASAR)\}

Pemetaan tabel query dibuat berdasarkan tabel relationship Nilai pada Gambar 12 dengan membandingkan tabel MHS, JURUSAN, dan MATAKULIAH yang telah dibuat relasinya sebagai berikut:

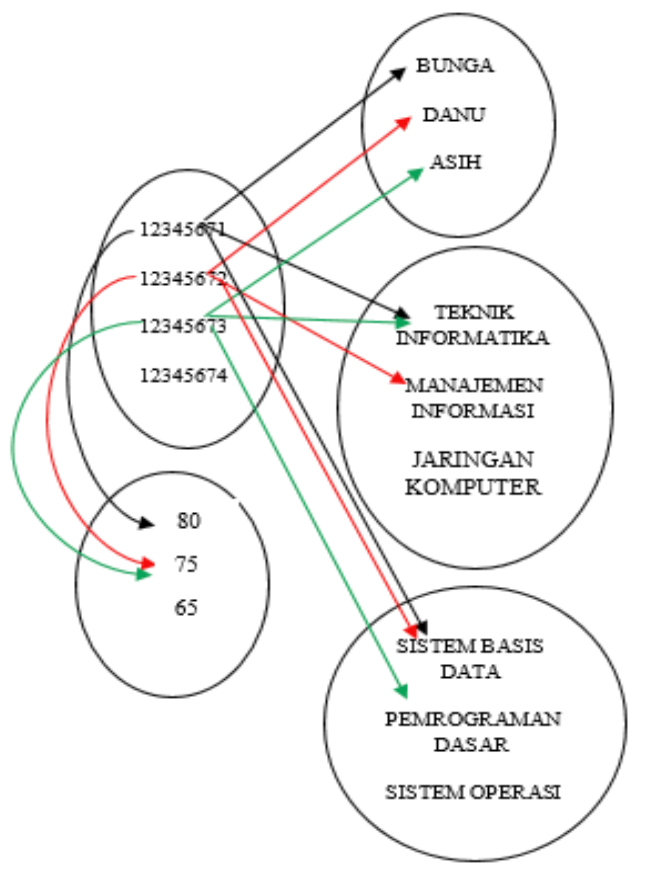

Gambar 13. Hasil Akhir Pemetaan Tabel Query 
Berdasarkan Gambar 13, maka hasil yang didapatkan antara lain adalah $\{(12345671$, BUNGA, TEKNIK INFORMATIKA, SISTEM BASIS DATA, 80), (12345672, DANU, MANAJEMEN INFORMASI, SISTEM BASIS DATA, 75), (12345673, ASIH, TEKNIK INFORMATIKA, PEMROGRAMAN DASAR, 75) \}.

Kesimpulan yang didapatkan dari diagram relasi pada tabel query: nilai yang mendapatkan lebih dari atau sama dengan 75 adalah Bunga dari Jurusan Teknik Informatika untuk Mata Kuliah Sistem Basis Data; Danu dari Jurusan Manajemen Informasi untuk Mata Kuliah Sistem Basis Data; Asih dari Jurusan Teknik Informatika untuk Mata Kuliah Pemrograman Dasar.

Pemetaan tabel relationship pada studi kasus yang penulis lakukan, ternyata jika menggunakan pemetaan dengan komposisi relasi menjadi timbul banyaknya kemungkinan terjadinya relasi, dikarenakan beberapa data yang sama. Hal ini disebabkan Foreign Key yang dihubungkan tidak unik. Misalkan $\mathrm{R}_{1} \mathrm{O} \mathrm{R}_{2}$ $=\{(12345671,201), \quad(12345671,202)\}$, padahal data aktualnya adalah (12345671,201), dapat dilihat pada Gambar 12. Berarti, pemetaan dari komposisi relasi hanya dapat dilakukan pada tabel yang berisi Primary Key dan setiap atributnya bersifat unik.

Oleh karena itu, tabel relationship dapat dipetakan ke dalam relasi secara biner berdasarkan jumlah atribut didalam suatu tabel. Semakin banyak atribut pada tabel, maka semakin banyak pemetaan diagram relasi yang harus digambarkan.

Walaupun semakin banyak pemetaan diagram relasi sehingga membuat diagram menjadi sangat kompleks. Hal ini dapat ditangani jika tabel-tabel tersebut dinormalisasikan dengan baik.

Berdasarkan hasil dari Gambar 13, eksplorasi data menjadi lebih mudah untuk menemukan data yang kemungkinan salah atau belum input.

Kemudian, pada penelitian ini penulis belum membahas bagaimana perannya kardinalitas suatu tabel berdasarkan Diagram Relasi. Hal ini dapat dilakukan pada penelitian selanjutnya beserta penerapannya didalam perancangan pada Aplikasi Sistem Informasi.

\section{SIMPULAN}

Berdasarkan pemetaan tabel relationship pada diagram relasi. Hasil yang didapatkan adalah \{(12345671, BUNGA, TEKNIK INFORMATIKA, SISTEM BASIS DATA, 80), (12345672, DANU, MANAJEMEN INFORMASI, SISTEM BASIS DATA, 75), (12345673, ASIH, TEKNIK INFORMATIKA, PEMROGRAMAN DASAR, 75) \}. Pemetaan ini sudah sesuai dengan tabel query yang sudah dibuat. Namun, penulis menemukan pada proses pemetaan. Jika menggunakan komposisi relasi, membuat banyaknya kemungkinan terjadinya relasi pada pemetaan, dikarenakan ada beberapa data yang sama. yang disebabkan Foreign Key yang dihubungkan tidak unik. Oleh karena itu, tabel relationship dapat dipetakan ke dalam relasi secara biner berdasarkan jumlah atribut didalam suatu tabel. Semakin banyak atribut pada tabel, maka semakin banyak pemetaan diagram relasi yang harus digambarkan. Walaupun diagram relasi menjadi sangat kompleks, hal ini dapat ditangani jika tabel-tabel tersebut dinormalisasikan dengan baik.

\section{DAFTAR PUSTAKA}

[1] N. A. Syaripul and A. M. Bachtiar, "Visualisasi Data Interaktif Data Terbuka Pemerintah Provinsi Dki Jakarta: Topik Ekonomi Dan Keuangan Daerah," J. Sist. Inf., vol. 12, no. 2, p. 82, Nov. 2016.

[2] E. W. Ambarsari, A. Ar Rakhman Awaludin, A. Suryana, P. M. 
Hartuti, and R. Rahim, "Basic Concept Pythagoras Tree for Construct Data Visualization On Decision Tree Learning," J. Appl. Eng. Sci., vol. 17, no. 4, pp. 468472, 2019.

[3] E. W. Fridayanthie and T. Mahdiati, "Rancang Bangun Sistem Informasi Permintaan Atk Berbasis Intranet (Studi Kasus: Kejaksaan Negeri Rangkasbitung)," J. Khatulistiwa Inform., vol. 4, no. 2, pp. 126-138, 2016.

[4] S. Khotijah, "Perancangan Database E-Learning Manajemen System untuk Pembelajaran pada Sekolah Menengah Pertama," STRING (Satuan Tulisan Ris. dan Inov. Teknol., vol. 1, no. 1, pp. 65-73, 2016.

[5] I. Solikhin, M. Sobri, and R. Saputra, "Sistem Informasi Pendataan Pengunjung Perpustakaan (Studi kasus: SMKN 1 Palembang)," J. Ilm. Betrik, vol. 9, no. 03, pp. 140-151, Nov. 2018.

[6] M. Septiani, N. Afni, and R. L. Andharsaputri, "Perancangan Sistem Informasi Penyewaan Alat Berat," JUSIM (Jurnal Sist. Inf. Musirawas), vol. 4, no. 02, pp. 127135, 2019.
[7] A. Aswani, N. Ransi, and R. Ramadhan, "Penerapan Operasi Himpunan Dan Fungsi Agregasi Pada Perancangan Basis Data Alumni Universitas Halu Oleo," semanTIK, vol. 4, no. 1, pp. 7-12, May 2018.

[8] E. W. Ambarsari and H. Herlinda, "Pythagoras Tree Applied For Determined Instagram Usage Habit Decision," SinkrOn, vol. 4, no. 2, pp. 56-61, 2020.

[9] L. Mukhlisulfatih, "Pendekatan Database untuk Manajemen Data dalam Meningkatkan Kemampuan Mahasiswa Mengaplikasikan Konsep Basisdata," in Konvensi Nasional Asosiasi Pendidikan Teknologi dan Kejuruan Indonesia (APTEKINDO), 2010, pp. 231-238.

[10] D. Puspita and Erlin, "Sistem Silsilah Keturunan Menggunakan Metode Komposisi Relasi," SATIN Sains dan Teknol. Inf., vol. 2, no. 2, pp. 9-16, 2013.

[11] M. Ratuanik, "Pemahaman Siswa Kelas VIII B SMP Santo Aloysius Turi Tentang Relasi dan Fungsi Setelah Penerapan PMRI," in PRISMA., prosiding seminar nasional matematika, 2019, vol. 2, pp. 813-820. 